This item was submitted to Loughborough's Research Repository by the author.

Items in Figshare are protected by copyright, with all rights reserved, unless otherwise indicated.

\title{
Parental influences on children's eating behaviour and characteristics of successful parent-focussed interventions
}

PLEASE CITE THE PUBLISHED VERSION

http://dx.doi.org/10.1016/j.appet.2012.09.014

PUBLISHER

(C) Elsevier

VERSION

AM (Accepted Manuscript)

LICENCE

CC BY-NC-ND 4.0

\section{REPOSITORY RECORD}

Witcomb, Gemma L., Claire V. Farrow, Emma Haycraft, and Caroline Meyer. 2019. "Parental Influences on Children's Eating Behaviour and Characteristics of Successful Parent-focussed Interventions". figshare. https://hdl.handle.net/2134/11244. 
This item was submitted to Loughborough's Institutional Repository (https://dspace.lboro.ac.uk/) by the author and is made available under the following Creative Commons Licence conditions.

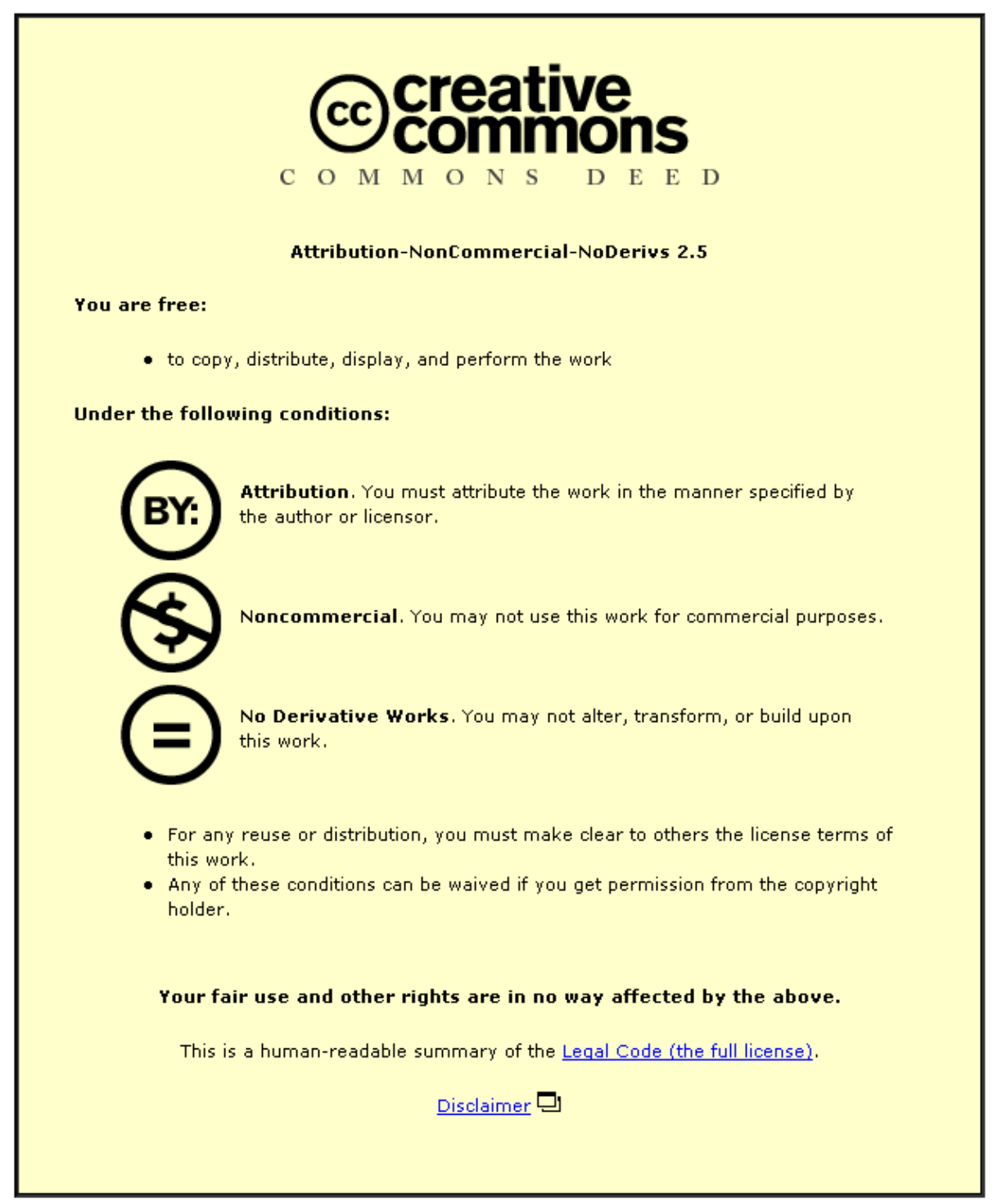

For the full text of this licence, please go to: http://creativecommons.org/licenses/by-nc-nd/2.5/ 
Parental influences on children's eating behaviour and characteristics of successful parent-focussed interventions.

\author{
Gemma L Mitchell, $\mathrm{PhD}^{1}$ * \\ Claire Farrow, $\mathrm{PhD}^{1}$ \\ Emma Haycraft, $\mathrm{PhD}^{1}$ \\ Caroline Meyer, $\mathrm{PhD}^{1}$
}

${ }^{1}$ Loughborough University Centre for Research into Eating Disorders, School of Sport, Exercise \& Health Sciences, Loughborough University, UK.

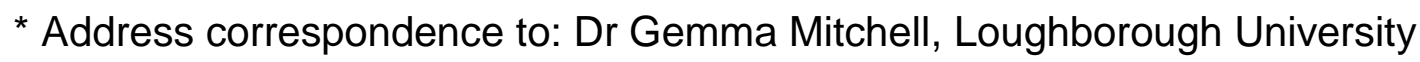
Centre for Research into Eating Disorders, School of Sport, Exercise \& Health Sciences, Loughborough University, Loughborough, Leicestershire, LE11 3TU, UK.

Email: G.L.Mitchell@lboro.ac.uk.

Telephone: +44 (0)1509 223084. Fax: +44 (0)1509 223940

Running head: Children's eating: parent influences and interventions. 


\begin{abstract}
Parental reports suggest that difficulties related to child-feeding and children's eating behaviour are extremely common. While 'fussy eating' does not pose an immediate threat to health, over the long-term, consumption of a poor diet can contribute to the development of a range of otherwise preventable diseases. In addition, the stress and anxiety that can surround difficult mealtimes can have a detrimental impact upon both child and parental psychological wellbeing. Since parents have a great influence over what, when, and how much food is offered, feeding difficulties may be preventable by better parental awareness. The aim of this review is to describe how parental factors contribute to the development of common feeding problems, and to discuss the merits of existing interventions aimed at parents/primary caregivers to improve child-feeding and children's eating behaviour. The potential for different technologies to be harnessed in order to deliver interventions in new ways will also be discussed.
\end{abstract}

Keywords: child eating difficulties, parental feeding practices, parenting style, interventions.

Acknowledgments

Dr Gemma Mitchell was employed on a grant funded by the Garfield Weston Foundation. There was no other funding for this work. 
Parental influences on children's eating behaviour and characteristics of successful parent-focussed interventions.

\section{Introduction}

Approximately $25-40 \%$ of infants and toddlers experience feeding problems, as reported by their caregivers (Reau, Senturia, Lebailly, \& Christoffel, 1996). Based on this, it is estimated that up to 289,266 of the children born in England and Wales in 2010 (Office for National Statistics, 2011) and 1,600,112 of the children born in the USA in the same year (Hamilton, Martin \& Ventura, 2011), will experience some feeding-related problem. Taken across the EU as a whole, this equates to around $31,603,20$ of the children born in 2010 (United Nations, 2012). This is concerning, since a poor diet in childhood often predicts poor diet in adulthood (e.g., Craigie, Lake, Kelly, Adamson, \& Mathers, 2011) and the development of a range of otherwise preventable diseases, such as obesity, cancer, and heart disease (e.g., Nicklas \& Hayes, 2008). This is costly, with recent figures reporting that the British healthcare system spent $£ 5.8$ billion in 2006-2007 treating illnesses related to inadequate nutrition and poor diet (Scarborough et al., 2011). In addition, child feeding problems are often associated with decreased parental emotional and psychological wellbeing (e.g., Blissett, Meyer, \& Haycraft, 2007). However, since many families experiencing non-clinical feeding problems do not receive professional help, parental mental health and well-being issues are less likely to be identified and treated. Thus, 
common feeding problems can leave both the parent and the child vulnerable to further negative health-related outcomes.

The definition of a non-clinical feeding-related problem is somewhat ambiguous due to the plethora of different terms that are used within the literature to describe problematic feeding and eating behaviours. Most child eating problems involve food refusal to a greater or lesser degree (Dovey, Farrow, Martin, Isherwood, \& Halford, 2009). However, 'food refusal' is an umbrella term which incorporates labels such as picky or fussy eating, poor appetite, food avoidance, neophobia, and infantile anorexia, to name a few. Feeding problems may present a risk to nutritional health (Galloway, Fiorito, Lee, \& Birch, 2005), but may not necessarily be associated with underweight (March \& Cohen, 1990), Importantly, as acknowledged by Bryant-Waugh, Markham, Kreipe, and Walsh (2010), child eating difficulties affect more than just the child, and have a wider impact on the family. Indeed, the relationships and interactions around feeding are important factors that play a role in the development and maintenance of eating difficulties.

This review focuses on the role of parental feeding practices in the development of non-clinical feeding problems; those aspects of children's eating behaviour that are not conducive to the development of a varied and nutritionally-balanced diet or a healthy relationship with food. It will begin by reviewing the literature related to parental feeding practices, before discussing the nature of the support that is currently available for parents and identifying the characteristics of 
successful interventions. Finally, new approaches to more interactive interventions which may prove fruitful are described.

\section{Parental influences on children's eating behaviour}

In general, parents tend to control what and when their young children eat. Frequently, they also attempt to control how much is eaten. As a result, parents' influence is significant - often well before a child can even walk or talk. This influence is reflected both by what is on the plate and the context in which it is offered. The following section reviews the ways in which the home mealtime environment and parental feeding practices influence children's eating behaviour and the impact on child adiposity.

\section{Exposure}

Research has found that children tend to require up to 15 exposures of a new food before it is 'trusted' and thus tasted (Wardle, Carnell \& Cooke, 2005) and a further 10-15 exposures to bring about a liking for the food (Wardle et al., 2003). One reason for this may be related to the expression of neophobia - a normal, developmental response that all children will experience, usually around the age of two years (for a review see Dovey et al., 2008). It is defined as the reluctance to eat, or the avoidance of, new foods, and is believed to be an evolutionarybased response that has evolved to ensure avoidance of threatening and potentially poisonous foods (see Pliner \& Hobden, 1992; Rozin \& Vollmecke, 1998). By repeatedly offering an initially rejected food, parents play a crucial role in transforming an unfamiliar food into a familiar one, and by doing so the innate neophobic response becomes diminished. Unfortunately, many parents 
are unaware of this requirement. Since the introduction of new foods between the ages of 5-7 months can be relatively easy and met with little resistance (Schwartz, Issanchou, \& Nicklaus, 2009), parents may not associate the rejection of foods at around the age of two years with a developmental phase. This is concerning, as research with both weaning babies (Maier, Chabanet, Schaal, Leathwood, \& Issanchou, 2007) and pre-school children (Carruth \& Skinner, 2000; Carruth, Ziegler, Gordon, \& Barr, 2004) has shown that parents typically do not persist in offering a rejected food beyond five attempts, and by 'giving up' too soon, the diet of the child can become unnecessarily limited (Aldridge, Dovey, \& Halford, 2009; Cashdan, 1994; Zajonc, 1968).

\section{Role-modelling}

Of course, the likelihood of a food even being offered for tasting is often inextricably linked to the likes and preferences of the parent. If parents themselves have a narrow diet, many foods will not appear on the table on enough occasions to allow for sufficient exposure (Carruth \& Skinner, 2000; Wardle et al., 2005) or for positive role-modelling, which has been associated with increasing children's acceptance of new foods (Jansen \& Tenney, 2001) and with children's intake of healthier foods (Palfreyman, Haycraft \& Meyer, in press). Exposure can also come from peers (Shepard \& Dennison, 1996), facilitated by school interventions (e.g., Heim, Stang, \& Ireland, 2009). However, the effects of peer modelling can be negative if fruit and vegetable rejection is seen (Hendy \& Raudenbush, 2000) and such effects can be hard to reverse, even with positive modelling (Greenhalgh et al., 2009). Therefore, while 
exposure is central to increasing familiarity, the behaviour of others - that occurs concurrently with the exposure and becomes associated with it - can be critical in encouraging or discouraging acceptance.

\section{Coercive feeding practices}

The parental behaviours and practices that accompany mealtimes have been identified as playing an important role in whether foods come to be accepted. For example, one common practice is the use of pressure to encourage eating (e.g., Haycraft \& Blissett, 2008). Pressure to eat can take many forms, including verbal prompts, physical prompts, and the use of incentives, such as other food as rewards. Overall, such practices are considered counter-productive.

Pressure to eat has been associated with increased neophobia (Fisher, Mitchell, Smiciklas-Wright, \& Birch, 2002; Wardle et al., 2005; but see Bourcier, Bowen, Meischke, \& Moinpour, 2003, for contrary evidence), food avoidance (Powell, Farrow, \& Meyer, 2011), decreased liking for and consumption of the to-beeaten food (Galloway et al., 2005; Galloway, Fiorito, Francis, \& Birch, 2006) and lower child BMI (in 6-8 year olds, Lee \& Keller, 2012; at age 2, Farrow \& Blissett, 2008). Indeed, retrospective reports have found that adults' food dislikes can be traced back to negative experiences involving pressure to eat (Batsell, Brown, Ansfield, \& Paschall, 2002) and enjoyment of eating is predicted by less pressure to eat (Webber, Cooke, Hill, \& Wardle, 2010).

Pressure to eat has also been associated with increased food consumption. Orrell-Valente et al. (2007) observed 142 families and found that $83 \%$ of 
children ate in direct response to parental pressure. Estimates of amount eaten due to parental pressure were made using a 4-point scale, from none (0), a little (1), a moderate amount (2), to a substantial amount (3). Based on this, it was estimated that $38 \%$ of children ate moderately to substantially more than they would have had there been no parental promoting. A recent study of 1218 mothers and their infants found that a greater percentage of assertive prompts and intrusiveness was associated with higher child adiposity at 36 months of age (Lumeng et al., 2012). This is consistent with other studies which have found that the frequency of maternal prompts was related to the number of calories consumed by 3.5 year olds (Drucker, Hammer, Agras, \& Bryson, 1999) and to higher child weight in 12-30 and 22-46 month old children (Kleges et al., 1983; Klesges, Malott, Boschee, \& Weber, 1986). Continually being coerced to 'clean your plate' and eat past satiety may undermine a child's ability to recognise and respond appropriately to their feelings of hunger and fullness, setting the foundations for problems with regulating their intake in the future (e.g., Carper, Fisher, \& Birch, 2000). Indeed, research has shown that feelings of fullness can be attenuated by distraction (Brunstrom \& Mitchell, 2006) and it may be this attenuation that is responsible for bouts of overeating. Thus, in a cruel twist, it appears that a parent's desire for their child to 'eat enough' can actually lead to mealtime negativity (Farrow \& Blissett, 2006a) and problems with over-eating and weight gain in the future (Farrow \& Blissett, 2006a; 2008).

$\underline{\text { Restriction, rewards, and using food to soothe }}$ 
Other parenting practices can also have maladaptive influences on children's eating behaviour (Benton, 2004). For example, overt restriction of foods has been associated with increased consumption of those foods when made freely available (e.g., Ventura \& Birch, 2008) and greater weight gain overtime (Clark et al., 2007). Covert restriction, however, appears not to be related with such effects (Ogden, Reynolds, \& Smith, 2006). The extent to which parents overtly restrict food may be related to the perceived weight status of the child, with parents using more restriction with infants who have a higher BMI (at 6-12 months; Brown \& Lee, 2011) or those perceived to be at risk of becoming obese (Faith et al., 2004). However, while greater restriction of food during infancy predicts lower child weight at age 2 (Farrow \& Blissett, 2008), by 5 years of age the use of earlier maternal restriction predicts greater child weight scores (Farrow, 2011; but see also Campbell et al., 2010). Therefore, although perceived to be successful in early life, overt restriction appears to be detrimental to children's ability to successfully regulate their intake when older.

Using food as a reward is also believed to have a detrimental effect on later appetite regulation and subsequent BMI (Puhl \& Schwartz, 2003). This is because the status of a food as a reward increases its affective value (Birch, Zimmerman, \& Hind, 1980), making it more desirable and more likely to be eaten to excess when freely available (Baughcum, Burklow, Deeks, Powers, \& Whitaker, 1998). In addition, using food to soothe emotions and 'to make things better' has been found to be associated with increased child BMI in 3-34 month old children (Stifter, Anzman-Frasca, Birch, \& Voegtline, 2011) and eating more 
food in the absence of hunger in 3-4 year old children (Blissett, Haycraft, \& Farrow, 2010); a behaviour which itself has been linked to overweight (Fisher \& Birch, 2002). This is concerning, since retrospective studies suggest that preference for previously restricted foods and emotion-induced overeating tend to persist into adulthood (Brunstrom, Mitchell, \& Baguley, 2005; Puhl \& Schwartz, 2003).

\section{Parenting Styles}

Thus far, parenting practices in relation to child feeding have been described. However, the extent to which parents choose to implement different practices, and in what way, may be related to their underlying parenting style; a characteristic that influences the emotional context of all aspects of parenting, including feeding (Darling \& Steinberg, 1993). Two dimensions of parenting style have been identified: demandingness and responsiveness (Maccoby \& Martin, 1983). Demandingness refers to using behavioural control over the child. Responsiveness refers to showing warmth and supportiveness to the child. Parents can score high or low on each of the dimensions, resulting in a four-fold classification of parenting styles: 1) authoritative (high demandingness/high responsiveness); (2) authoritarian (high demandingness/low responsiveness); (3) indulgent (low demandingness/high responsiveness); and (4) uninvolved (low demandingness/low responsiveness). Many studies on general parenting behaviours have found that authoritative parenting is associated with the most positive child outcomes (e.g., Darling \& Steinberg, 1993; Maccoby \& Martin, 1983). Similarly, in relation to feeding, the authoritative style of providing rules 
but in a positive context is associated with the development of the healthiest eating habits (Ventura \& Birch, 2008), including greater fruit and vegetable intake (Blissett, 2011).

However, whether a parent's general parenting style predicts their specific feeding style is not completely clear. Recently, Rigal, $\underline{\text { Chabanet, Issanchou, and }}$ Monnery-Patris (2012) assessed aspects of parenting around mealtimes in a French population and found that feeding difficulties were associated with: 1) permissive feeding styles and practices that fulfil the child's desires, such as only preparing a child's preferred meal in order to avoid mealtime conflict; and 2) an authoritarian feeding style including the use of contingencies and coercive practices in order to force a child to eat a rejected food. However, a general difficulty with drawing conclusions based on such studies relates to the direction of the effects. It is unclear whether general parenting style predicts feeding styles, which may then be instrumental in the development of feeding difficulties, or whether feeding difficulties predict the use of particular feeding styles, irrespective of the greater general parenting style.

With regard to BMI, both indulgent parenting styles (Olvera \& Power, 2010) and indulgent feeding styles (Hughes, Power, Fisher, Mueller, \& Nicklas, 2005) have been shown to be associated with higher child BMI than authoritarian styles (age ranges 3-8 years). Some studies have found effects on BMI of fathers' but not mothers' permissive and disengaged parenting styles (e.g., Wake, Nicholson, Hardy, \& Smith, 2007) while other studies report no effects of either parents' parenting style on BMI (e.g., Blissett \& Haycraft, 2008). Therefore, although both general parenting style and feeding-related style appear to be 
important, the nature of the underlying relationship between the two, and the effect on child adiposity, is less clear.

Summary of parental influences: The research presented thus far illustrates the significant impact that parental feeding practices (exposure, modelling, pressure to eat, use of restriction, rewards, and using food to soothe) and parenting and feeding styles can have on children's food preferences and intake, which can hinder the development of appropriate regulatory controls and influence subsequent BMI. An appreciation of how these factors affect the establishment of a healthy and varied diet is essential if interventions are to be effective at improving children's nutritional health and well-being. The following section reviews the effectiveness of different approaches to interventions aimed at improving parental feeding practices through increased education.

\section{Parent-focussed interventions for non-clinical feeding difficulties}

What, when, and how much food is offered to a child at mealtimes is the responsibility of a child's parents/caregivers, most often the mother (e.g., Blissett, Meyer \& Haycraft, 2006; Robinson, 2000; Savage, Fisher, \& Birch, 2007). However, what and how much is eaten is determined by the child. Maladaptive feeding practices often derive from a parent's anxiety about the health and wellbeing of their child; the belief that their child is unable to selfregulate (Tan \& Holub, 2011), is perceived to be underweight (Galloway et al., 2006) or overweight (Gregory, Paxton, \& Brozovic, 2010a), or over responsive to food (Gregory, Paxton, \& Brozovic, 2010b). When parents' beliefs regarding 
'what, when and how much' are inaccurate (McConahy, Smiciklas-Wright, Mitchell, \& Picciano, 2004; Pugliese, Weyman-Daum, Moses, \& Lifshitz, 1987), and/or when children's patterns of acceptance and rejection are not consistent with requirements for a balanced diet and healthy weight and growth (Dennison, 1996; Fisher \& Kral, 2008; Pugliese et al., 1987), interventions are required which provide the necessary information and support to address this discrepancy.

Parents experiencing feeding difficulties often turn to health professionals for advice, but most will also seek support elsewhere (Gildea, Sloan, \& Stewart, 2009). Friends and family members (Heinig et al., 2009) and media, such as the internet and books (Olson, Horodynski, Brophy-Herb, \& Iwanski, 2010), are often cited as favoured sources of information. Parents' tendencies to seek information from a variety of sources may reflect confusion over conflicting (Walker, 2005), difficult to follow (Olson et al., 2010), or inaccurate (Carruth \& Skinner, 2001) advice; a belief that professional advice is not suited to their individual needs (Horodynski et al., 2007), or low perceived credibility of the healthcare professional (Heinig et al., 2009). Indeed, our own observations in the UK have found that many mothers choose to self-manage their child's feeding difficulties due to a perceived lack of education and training of health visitors and a lack of educational resources available for parents (Mitchell, Farrow, \& Haycraft, 2012). 
Feeding-related advice tends to centre around educating parents-to-be on the benefits of breastfeeding. Once their baby is born, advice is restricted to supporting women to continue breastfeeding for at least 6 months and mothers report that it is difficult to get advice past this stage (Fägerskiöld, Wahlberg, \& Ek, 2001; Mitchell et al., 2012). Information regarding starting solid feeding is given to parents by their heath professional when their infant is around 4-6 months old - a time when many parents have already begun to introduce solid foods. However, this takes the form of simple printed literature which often fails to mention some of the most important factors that should be consider when feeding a child. Schwartz, Scholtens, Lalanne, Weenen, and Nicklaus (2011) reviewed feeding guidelines from the WHO, EnNutNet, USA, UK and France and found differences in which themes were covered, and in how much detail. For example, while research has confirmed that repeated exposure to a food is important in order to bring about acceptance and liking (see Cooke, 2007), this message is not conveyed in UK or French guidelines, although it is in WHO, EU and American guidelines. None of the guidelines elaborate on how to enhance exposure to variety. The UK guidelines do suggest that parents do not forcefeed their child if they refuse to eat and do acknowledge that food refusal can be stressful for parents; "Try to stay calm even if it's very frustrating" (Department of Health, 2009, p.59). Yet, neither the UK nor the other international guidelines offer any practical tips on how to deal with food refusal or specifically explain the detrimental effects of coercive practices. Overall, many parents may struggle to improve their child's food fussiness due to a lack of trusted, accurate and, importantly, tangible advice. 
Until recently, feeding interventions have tended to be aimed at providing effective treatments for clinically-significant feeding disorders, as opposed to addressing the more common concerns, such as increasing acceptance of fruits and vegetables or expanding dietary variety. However, since seemingly minor feeding issues can develop into something more clinically significant, early interventions that address these common difficulties would appear to be essential. To date, interventions directed at parents whose children are experiencing non-clinical feeding problems are somewhat limited and tend to fall into one of two categories: 1) educational literature (e.g., leaflets); 2) educational group programmes. However, other types of interventions are appearing in the commercial sector and online. These interventions are described below with each of their merits discussed in turn.

\section{Educational Literature}

Provision of general information in leaflet format can be regarded as a basic type of intervention. The use of leaflets by health visitors is widespread, partly due to public demand and partly due to time-constraints (Hunter, 2005). However, a survey found that despite $96 \%$ of health visitors giving leaflets out, confidence in the ability of a leaflet to increase knowledge or change behaviour was low (29\% and 3\% respectively; Murphy \& Smith, 1993).

Interventions that have specifically assessed the use of leaflets to improve children's eating behaviour have had mixed results. Wardle et al. (2003) 
compared the effects of a leaflet, targeted exposure, or no intervention on 2-6 year old children's liking for an already moderately-liked vegetable. Specifically, liking, ranking, and consumption of the target vegetable were compared in children whose parents were either given 1) a leaflet containing advice and suggestions on how to increase child fruit and vegetable consumption, 2) instructions to expose their child to the vegetable daily for 14 days, avoiding offering any reward for consumption, or 3 ) no instruction or advice. No evidence of a significant positive effect of the leaflet intervention was found. Rather, significant increases in all three outcomes (liking, ranking, consumption) were only seen in the exposure group. One possible explanation for the lack of effect of the leaflet is drawn from Wardle and Huon's (2000) finding that telling children that a food was 'healthy' reduced acceptance of the food. Since the leaflet emphasised health issues, parents may have stressed this more with their children and inadvertently influenced liking.

Converse findings have been recently reported in the 'Mealtime Magic' intervention (Inglis, Docherty, \& Pryke, 2010) which found leaflets to be beneficial. In this intervention, health professionals in five primary care practices in Worcestershire (UK) distributed leaflets to all parents of children under age 5 presenting to primary care over a 6 week period. The leaflets were given in conjunction with verbal reinforcement of three main messages: 1) that foods should be presented up to 20 times to become familiar and popular and increase the chances of children choosing it for themselves; 2) that diets are healthier if they contain lots of different foods rather than sticking to a few 
favourites; and 3) that caregivers should avoid telling children to eat everything on their plate if it makes them eat more than they want. This latter message was reported to be particularly helpful, although for the majority (82\%; 115 parents) this was not new information. However, $30-52 \%$ of parents did report that reading the leaflet increased their confidence in implementing what they already knew. Therefore, the leaflet was valuable both as a primary source of new information and as a secondary reiteration that served to encourage behaviour change. However, as the leaflet was given in conjunction with verbal reinforcement, it is unclear how effective the leaflet alone was in the changes reported.

Mixed results of using literature to improve parental feeding practices have also been reported by Essery, DiMarco, Rich, and Nichols (2008). These researchers compared the efficacy of weekly newsletters and a booklet given at the start of the intervention. While no positive changes in behaviour were associated with the provision of the booklet, the same information presented in weekly newsletters across 12 weeks was associated with less pressure to eat. This again suggests that tailoring the provision of information to the target group is important; in this case, fitting parents' lifestyles. Busy parents may be more likely to read a newsletter that is pinned to the refrigerator, than reference information from a book that has been filed away on a bookshelf.

Overall, research investigating the effectiveness of leaflets for promoting healthy feeding practices in children is relatively scarce. As such, the real 
benefits of these remain largely unknown. However, based on research in other health-related areas, the extent to which leaflets are effective as a stand-alone intervention is likely to be limited. Rather, leaflets provided in conjunction with verbal reinforcement and tailored to the target group, are more likely to be effective.

\section{Educational Group Programmes}

In light of the general ineffectiveness of printed educational literature to influence parental feeding practices, increasing attention is being paid to developing more hands-on interventions that offer parents a greater depth of understanding about child feeding.

\section{Fun not Fuss with Food}

The 'Fun not Fuss with Food' programme (Fraser, Wallis, \& St John, 2004) is based on social learning principles to increase positive interactions and reduce coercive and inconsistent parenting practices. Parents with children between the ages of 2 and 10 years were recruited to take part in the 2.5 hour programme via referral from a doctor, health worker, or self-referral. Seventyfive families took part and parents received education in childhood nutrition and learnt techniques such as verbal instruction, role modelling, and positive reinforcement. Pre- to post-intervention comparisons of scores on the revised Children's Eating and Mealtime Behaviour Inventory (CEBI-R; Archer, Rosenbaum, \& Streiner, 1991) found a significant decrease in the overall total problem eating scores, in all the subsections separately (maternal attitudes and 
feelings, child behaviour compliance and manual/oral motor development), and in the total parent problem scores. The percentage of parents whose responses would indicate their child required clinical intervention also significantly decreased. These results suggest that a single-session intervention can be sufficient to produce positive changes in problem eating behaviour. Indeed, other single session interventions have similarly reported changes in attitudes and practices (e.g., Eliassen, Miller, \& Guskey, 2010). However, the extent to which such changes are sustained over time is unknown. The result of the Fun not Fuss with Food programme does suggest that interventions do not necessarily need to be one-on-one, with a single family unit treated alone. Rather, group interventions can be effective and it may even be the group dynamic itself, offering support and shared experiences that are central to the effectiveness reported.

\section{Fun with Food}

A similar group intervention, 'Fun with Food' (Haywood \& McCann, 2009) emerged as a result of increasing numbers of non-clinical feeding problems being seen within ethnic minority families living in London (UK). Health visitors referred to the programme 20 families with children under 5 who were experiencing feeding difficulties including poor appetite, unvaried diet, reluctance to try new foods, poor self-feeding, and excessive milk consumption. The intervention consisted of four weekly sessions, each lasting 1.5 hours, with a follow-up one month later. The aim of the intervention was prevention tackling feeding issues at a young age before greater difficulties develop. The 
format of each session consisted of group discussion, hands-on interaction with food, and setting weekly challenges to tackle specific behaviours (e.g., resisting tantrums around snack food). Feeding difficulties were assessed with the reduced 10-item version of the Behavioral Pediatrics Feeding Assessment Scale (BPFAS; Crist et al., 1994). Only 12 families completed the measures at all of the time points. However the trend from this small sample did show a reduction in problem scores on the BPFAS, most notably parental worry. Scores related to children's appetite showed an improvement, as did the range of food eaten and enjoyment of food, although the latter two were not maintained at follow-up, but were greater than pre-intervention levels. The researchers state that families were responsive to the predictable format of the intervention sessions. In addition, the flexibility of topics discussed allowed parents to gain information tailored directly to their family and their problems and the group setting helped to reduce parental anxiety by hearing other parents' feeding difficulties.

The main aim of both of the programmes reported here was to increase parents' knowledge and understanding of child feeding in order to decrease feeding problems and increase healthy feeding practices. Educational sessions of this nature are often undertaken in groups due to economic reasons of time, money, and resources. However, both programmes reported that parents found the emotional and social support that occurred as a result of the group dynamic to be important. Therefore, the group setting may be advantageous through the additional psychological support that is offers, albeit unintentionally. 


\section{Emotional support as a vehicle for intervention}

Previous research has shown that mothers of children with feeding problems often have higher levels of depression and anxiety (Blissett et al., 2007; Chatoor, Hirsch, Ganiban, Persinger, \& Hamburger, 1998; Coulthard \& Harris, 2003; Duniz et al., 1996; Lindberg, Bohlin, Hagekull, \& Palmerus, 1996; Whelan \& Cooper, 2000), emotional distress (Budd et al., 1992), parenting stress (Singer, Song, Hill, \& Jaffe, 1990; Spender et al., 1996) and poorer problem-solving abilities (Ünlü, Aras, Guvenir, Buyukgebiz, \& Bekem, 2006). Farrow and Blissett (2006b) also reported that in a group of ninety-nine mothers the most common factor associated with feeding difficulties was low self-esteem and feelings of social isolation. Therefore, it is apparent that mothers of children with feeding problems experience significant negative emotions. Since the interaction that takes place between the mother and the child is likely to be influenced by the emotional state of the mother (Sanders, Patel, le Grice \& Shepherd, 1993), this is an important consideration when investigating the factors involved in feeding difficulties. However, many interventions fail to acknowledge this.

Jones and Bryant-Waugh (2012) recently piloted an intervention that had the specific aim of improving parental emotions and empowering mothers to feel more positive about their role as caregivers. They recruited mothers who had been referred to the Feeding and Eating Disorders Service at Great Ormond Street Hospital (London, UK). The authors hypothesised that by improving a mother's emotional health, she becomes better equipped to approach feeding 
problems. Ten mothers took part in six weekly, 90 minute sessions that focussed on providing emotional and educational support, addressing low mood, parenting stress and feeding related concerns. At the start of the intervention, the majority of participants had clinically significant levels of anxiety, depression and parenting stress. At the end of the intervention these levels had reduced, albeit non-significantly. However, importantly, clinically significant improvements were seen in measures specifically related to maternal perception of child feeding, in particular, mothers' ratings of the severity and number of child feeding problems. Therefore, it would appear that the group dynamic was successful in encouraging mothers to re-evaluate their child's feeding difficulties. Mothers did report that the group offered them opportunities for emotional expression and reduced their sense of isolation and self-blame. This suggests that interventions which take a more socially-supportive role have the potential to bring about positive changes in maternal perceptions of child feeding problems and, as a result, may influence the feeding practices subsequently used. Indeed, if parents understand children's eating behaviour and their own actions better, interactions around feeding are likely to be improved, resulting in positive changes in children's behaviour (real or perceived) and mothers' feelings. It should be noted, however, that since only 10 mothers were involved, some caution is advised when interpreting these pilot data.

There is some evidence that the effectiveness of education-based interventions is largely related to the educational status of the families involved, with higher education level being associated with better outcomes (Mahoney, Kaiser, 
Girolametto, \& MacDonald, 1999). However, other studies have failed to find links between demographic status and intervention outcomes (Archer \& Streiner, 1992). The improvements in children's appetite, dietary variety, and enjoyment of eating observed by Haywood and McCann (2009) would suggest that education-based interventions can be effective even when there are language / cultural barriers if flexibility exists to allow one-on-one opportunities for further explanation and support. Furthermore, the findings from Jones and BryantWaugh's (2012) pilot group intervention suggest that it may the social support that is generated in group educational-based programmes that is an important influential factor. If this is the case, it would seem important that the leaders and participants of group-based interventions are from similar social and/or ethnic backgrounds in order to minimise the potential for social barriers that may hinder participants' ability to be open and connect with the other participants.

\section{Commercial Programmes}

With rising levels of childhood obesity comes an increasing number of commercial interventions. One such intervention is Mange Tout (www.mangetoutkids.com). This is a healthy eating programme for parents and children that aims to help children "discover the fun in food, learn some basic nutrition and inspire their young appetites so they can enjoy the benefits of a healthy diet". The classes aim to expose children to fruits and vegetables through the use of characters, activities, games and songs, in order to encourage a gradual change in attitude and taste. This hands-on approach is 
believed to help dispel some of the fears and preconceptions that children may have about accepting a new food.

There has been no quantitative assessment of the effectiveness of this intervention in increasing children's willingness to taste and eat new foods and to increase fruit and vegetable consumption. However, similar sensory-related education-based programmes with older children have reported reductions in neophobia and increases in willingness to taste novel and unfamiliar foods (Mustonen \& Tuorila, 2010; Reverdy, Chesnel, Schlich, Köster, \& Lange, 2009) although the effects were not always apparent at follow-up (Reverdy et al., 2009). To date, the Mange Tout programme has been well received by parents and testimonials report vastly improved eating habits, and happy children. The success has led to the London-based programme being rolled out across the UK, with plans to launch the programme in Australia and New Zealand. It has also been taken on by a number of high-end hotels in Europe. However, as with many commercial interventions, the extent to which they are able to make an impact on those in need is questionable. Attendance at Mange Tout classes is costly, working out at around $£ 439$ a year. This is simply unaffordable for many families, particularly those on a low-income. Furthermore, the expansion of this programme into high-end hotel chains again likely limits the recipients to those from higher socio-economic backgrounds.

Interventions that are associated with commercial companies are also becoming more commonplace. An example of one such intervention is Taste for 
Life (www.tasteforlifenursery.com), a preschool education programme by Organix - a UK company that produces organic, healthy snacks for babies and toddlers. The programme is based on teaching parents the importance of exposing children to a wide variety of fruits and vegetables and allowing children to become familiar with and, importantly, interested in the food in a context independent from eating. Parents are able to access online resources and information that encourage interactive ways of presenting fruits and vegetables, along with activity sheets including game play and recipe ideas. A major advantage of this programme would appear to be the acknowledgment that children should not be put under pressure to try a food. Rather, exposure in all of its forms is considered important; through touching, playing, and cooking, as well as eating. Parents can download certificates and reward charts that can be used to reward children for touching, licking, tasting, or cooking with a fruit or vegetable. This is important since it shows parents that touching and interacting with food is an achievement and an important step in eventually accepting and enjoying eating a food.

As with Mange Tout, Taste for Life has yet to be quantitatively evaluated and so its effectiveness as an intervention has not been assessed. Furthermore, a problem with all commercially-driven interventions is the extent to which parents trust their sincerity. During our own focus groups with mothers (Mitchell et al., 2012) we have heard how health messages delivered from parenting-related companies tend to be distrusted on the basis that there is an additional, underlying motive. As a result, interventions from commercial companies may 
not be effective if parents feel that the advice is driven by a desire to make profits and not by a desire to improve children's diet and eating behaviour.

Summary of education interventions: There are two avenues to delivering educationally-based interventions to parents; one is through traditional healthcare and research-led initiatives, the other is through the growing number of commercial programmes that are available. The success of both types of parent-focused education interventions may be influenced by more than just the content of the information being presented. Rather, the context in which it is presented appears to be extremely important. More interactive programmes are superior to printed literature, possibly due to the additional emotional and psychological benefits gained from sharing experiences as part of a group, such as decreased stress and increased confidence (Barlow, Smailagic, Huband, Roloff, \& Bennet, 2012). Indeed, Farrow and Blissett (2006b) have found that social isolation is often reported alongside feeding problems. Group interventions are likely to reduce feelings of social isolation, improve mothers' emotional wellbeing and, subsequently, interactions around feeding may be improved. However, research into group behaviour from other areas of social psychology would suggest that a mismatch between the characteristics of the group and those of the individual participant would undermine any potential positive effects gained from a group dynamic (Festinger, 1950). Furthermore, if this mismatch leads to information being regarded as irrelevant, or in the case of commercial interventions distrusted, then it is unlikely to be successful. Taken together, this suggests that the characteristics of an effective intervention 
are that it is: 1) group-based; 2) consisting of parents from similar backgrounds;

3) tailored in order to be inclusive; and 4) free from any overly commercial references that may undermine trust.

\section{Harnessing technology for interventions}

In line with the increasing use of technology within all realms of everyday life, interventions delivered through technological devices may prove to be an effective and cost-efficient way of reaching a wide range of parents. Rather than simply putting educational literature online, new technologies have the advantage of being able to deliver very interactive experiences, embedded with social networking facilities, which offer a more engaging experience.

\section{Mobile Apps}

Apps are software programs that can be downloaded onto a mobile device, such as a smartphone (iPhone, Android phone, or Blackberry) or a tablet PC (e.g., an iPad). Recent reports stated that mobile apps are now being used more than the traditional internet (Flurry, 2011a) and that there will be 48 billion app downloads in 2015 (Flurry, 2011b). Apps have begun to be used to address a number of health-related behaviours. In November 2010 there were 17,000 health-related apps (Larkin, 2011) and this number is set to increase as apps become increasingly recognised as valuable educational or symptommanagement tools by both commercial companies and health care professionals (Mertz, 2012). However, one issue of concern relates to the largely unregulated content of apps (Abroms, Padmanabhan, Thaweethai, \& 
Phillips, 2011). Indeed, in relation to child feeding, there are a number of apps available that pertain to offer advice and tips to parents struggling with a fussy eater, however, the credibility of these apps is lacking. This problem is currently under review by the US Food and Drug Administration (Larkin, 2011) and regulatory guidelines may be being developed.

Despite this, the use of apps as vehicles to deliver health interventions has great potential. Evaluation of health-related apps that have been developed scientifically suggests that they are effective in engaging users, enhancing traditional clinical interventions, and improving both intermediate and clinical health outcomes (Gibbons et al., 2009). In particular, they have the potential to improve health disparities by increasing patient access to health-improving treatments and interventions among those that may not seek professional medical advice elsewhere (Gibbons et al., 2009). The latter point may be particularly true for many parents, particularly those from lower socio-economic backgrounds, who may be more likely to seek help with feeding difficulties online (Brodie et al., 2000).

Apps are also able to incorporate the social support element that has been previously highlighted as important in traditional, face-to-face group education programmes (Jones \& Bryant-Waugh, 2012). For example, an existing on-line programme that has been made available as an app is 'Habit Changer: Feeding Your Kids' (www.habitchanger.com). This is one of a number of 42-day programmes that are designed to use cognitive behavioural therapy to help with 
negative behaviours, such as smoking, unhealthy eating, and stress. The Feeding Your Kids programme aims to improve diet and nutrition by showing parents how to make changes to introduce children to healthier foods and develop healthier eating habits. The app looks at a broad range of children's eating-related issues and is available for free, in two languages, reflecting the need to allow parents of all economic and ethnic backgrounds to access the resource. The social support element is present through the inclusion of personal accounts from real parents and a social networking feature that allows parents to share their experiences with one another. Social networking exchanges occur in real-time and are increasingly becoming a more comfortable and familiar form of communication for many. Thus, the social support identified by Jones and Bryant-Waugh (2012) may easily be provided through the use of informal, mobile interventions as opposed to more formal, static group interventions. However, the extent to which a mobile app can be a useful tool will be related to the motivation of the parent to use and engage with it. To be motivating, it has been suggested that apps need to be informative, personalised, social, and include gaming features (Detecon Consulting, 2011).

\section{The Baby Feeding Simulator}

Another way in which technology can be used as a vehicle to improve child feeding practices is by providing safe opportunities to learn by 'doing' (Schank, Berman \& Macpherson, 1999). Indeed, programmes teaching behavioural reinforcement techniques to parents have found that written instructions alone are not sufficient. Rather, parents often require verbal, rehearsal, and/or 
modelling instruction also (Mueller et al., 2003). In these programmes, parents learn behavioural reinforcement techniques and then implement these with their child. However, the anxiety and stress that has become concurrent with feeding still exists. Recently, a novel and beneficial approach that teaches parents how to deal with problematic feeding situations away from the situation itself has been developed (Petrasova, Farrer, Czanner, Chalmers, \& Wolke, 2009a, 2009b; Petrasova, Czanner, Chalmers, Farrer, \& Wolke 2010a; Petrasova et al., 2010b). Currently aimed at infant feeding, virtual reality technology has been used to allow parents to 'feed' a virtual baby who can be programmed to respond in different ways depending on five parameters; distraction, tiredness, happiness, hunger, and liking for food taste and/or texture (Petrasova et al., 2010a). According to different combinations of these parameters, and how the parent acts (e.g., positioning of the spoon), the baby expresses different facial and bodily movements. Changes in one parameter will influence many. For example, if the baby becomes tired and the parent still tries to feed him, the value of happiness will decrease. This is accompanied by output feedback that the parent sees, for example, refusing food might involve head turning and hand movements or sounds expressing dissatisfaction or tiredness.

An advantage of this novel intervention is that real-life interaction with the child is not required. Therefore, different scenarios, and associated emotions, can be worked through without the risk of causing stress to the child or their parent. Importantly, it can be used pre-weaning to teach parents, in a relaxed way, what behaviours their child may elicit and how to deal with these. Therefore, it 
represents a possible preventative intervention. The hope is that by offering training using a virtual baby, parents will be better prepared to deal with any common feeding problems that their own child might exhibit, thus preventing them from escalating into more clinically-significant issues. To date, this virtual baby feeding simulator is still being developed and so the extent to which the possible benefits will be realised is unclear. However, virtual reality simulators have been useful in other domains where training under real-life conditions is emotionally-charged. For example, medical students trained using an obstetric birthing simulator had a better understanding of and comfort with basic obstetric procedures than those whose training involved attending to women already in labour (Deering, et al., 2006).

Although the virtual baby is able to elicit realistic feeding behaviours, it is a simulation and so lacks ecological validity. Indeed, absent is the emotional component that only a parent can experience. Evaluation of the simulator has to date only addressed its playability and user-interface and therefore not all participants who have taken part in these evaluations have been parents. Although all participants have reported experiencing stress, anger, or anxiety when food was refused and feeling happy when the baby ate (Petrasova et al., 2010a), the extent to which these feelings are similar in magnitude to those experienced when a parent is feeding their own offspring is unclear. Rather, in this instance, with many participants not being parents themselves, the emotions experienced could simply be a reflection of their desire to 'win the game' by having the baby eat the food. Since the nature of the parent-child 
relationship is hugely influential in the aetiology of feeding problems, this would appear to be an important component of any intervention. Nevertheless, the fact that this intervention could be implemented before feeding even begins makes it a valuable resource.

\section{Discussion}

Non-clinical feeding problems are extremely common, yet they can have serious adverse psychological and nutritional consequences. At present, parents are poorly supported in understanding why feeding problems in childhood can develop and what they can do to encourage the development of a healthy, varied, and balanced diet. As such, there is a real need to try to address the underlying causes of common feeding problems and equip parents with the knowledge and skills to tackle these when they occur. There are a number of factors that can contribute to non-clinical feeding problems yet, unfortunately, many parents are simply unaware of these. A recent editorial in The Lancet stated that health policies should offer "clear and tangible support to effective education for families on how important a good diet is to their children's growth, health, and future" (Horton, 2010, p.69). At present the depth of education offered to parents is limited and, as a result, these important health messages are not being well articulated.

Arguably, feeding-related advice is being given too late. Rather, education before the mother has given birth, as part of pre-natal care would be better suited to educating parents about common feeding problems, why they occur, 
and the importance of responding appropriately. Such a preventative approach, that sees parents educated before they become overwhelmed by a difficult feeding situation, would undoubtedly benefit the learning process and, it is predicted, reduce the number of reported feeding problems and associated negative emotional and psychological effects. Ultimately, by empowering parents early, the nutritional and emotional wellbeing of children can be improved.

The interventions described here cover those aimed at educating parents and caregivers. These take the form of leaflets, educational group programmes, and commercial programmes. Although such interventions have shown promising results, it is clear that their effectiveness is often related to the ability of the parent and/or child to engage with the materials. The importance of social support has been highlighted as a potential critical factor that may be often overlooked when designing educational interventions for parents. Future interventions should look to combine social support with educational content. Social networking facilities, although difficult to monitor, may provide one solution and novel interventions that harness the technologies which are being used in everyday life may prove useful for future interventions. In this review, the potential for interventions to be delivered 'in-your-hand' via mobile apps has been discussed and there is great scope for developments in this area. Finally, the use of baby feeding simulators has been described in order to illustrate how advances in technology may be able to provide useful preventative interventions that offer the kind of 'hands-on' education that cannot be ethically 
provided by any other means. However, it is important to note that such novel interventions have not yet been rigorously and scientifically tested, and so their effectiveness must be interpreted with caution.

In conclusion, many feeding problems may be avoided by the provision of better and timelier education for parents. Future interventions that use technology to deliver education and support in an interactive way may prove more effective in promoting understanding and providing support whilst being more cost-effective. 


\section{$\underline{\text { References }}$}

Abroms, L.C., Padmanabhan, N., Thaweethai, L., \& Phillips, T. (2011). iPhone Apps for Smoking Cessation: A Content Analysis. American Journal of Preventive Medicine, 40(3), 279-285.

Aldridge, V.K., Dovey, T.M., \& Halford, J.C.G. (2009). The role of familiarity in dietary development. Developmental Review, 29(1), 32-44.

Archer, L.A., Rosenbaum, P.L., \& Streiner, D.L. (1991). The children's eating behaviour inventory: Reliability \& validity results. Journal of Pediatric Psychology, 16, 629-642.

Archer, L.A., \& Steiner, D.L. (1992). The children's eating behaviour inventory: Further psychometric properties. Unpublished manuscript, McMaster University at Ontario.

Barlow, J., Smailagic, N., Huband, N., Roloff, V., \& Bennett, C. (2012). Groupbased parent training programmes for improving parental psychosocial health. Cochrane Database of Systematic Reviews, 6, CD002020. DOI: 10.1002/14651858.CD002020.pub3

Batsell, R. W., Brown, A. S., Ansfield, M. E., \& Paschall, G. Y. (2002). You will eat all of that!: A retrospective analysis of forced consumption episodes. Appetite, 38(3), 211-219.

Baughcum, A.E., Burklow, K.A., Deeks, C.M., Powers, S.W., \& Whitaker, R.C. (1998). Maternal feeding practices and childhood obesity-a focus group study of low-income mothers. Archives of Pediatrics \& Adolescent Medicine, 152, 1010-1014. 
Benton, D. (2004). Role of parents in the determination of the food preferences of children and the development of obesity. International Journal of Obesity, 28, 858-869.

Birch, L.L., \& Fisher, J.O. (1998). Developments of eating behaviours among children and adolescents. Pediatrics, 101, 539-549.

Birch, L.L., McPhee, L., Steinberg, L., \& Sullivan, S. (1990). Conditioned flavour preferences in young children. Physiology \& Behaviour, 47, 501-505.

Birch, L.L., Zimmerman, S., \& Hind, H. (1980). The influence of social affective content on preschool children's food preferences. Child Development, 51, 856-861.

Blissett, J. (2011). Relationships between parenting style, feeding style and feeding practices and fruit and vegetable consumption in early childhood. Appetite, 57(3), 826 - 831.

Blissett, J. \& Haycraft, E. (2008). Are parenting style and controlling feeding practices related? Appetite, 50, 477-485.

Blissett, J., Haycraft, E., \& Farrow, C. (2010). Inducing preschool children's emotional eating: relations with parental feeding practices. American Journal of Clinical Nutrition, 92, 359-365.

Blissett, J., Meyer, C. \& Haycraft, E. (2006). Maternal and paternal controlling feeding practices with male and female children. Appetite, 47, 212-219.

Blissett, J., Meyer, C., \& Haycraft, E. (2007). Maternal mental health and child feeding problems in a non-clinical group. Eating Behaviors, 8, 311-318. 
Bourcier, E., Bowen, D.J., Meischke, H., \& Moinpour, C. (2003). Evaluation of strategies used by family food preparers to influence healthy eating. Appetite, 41, 265-272.

Brodie, M., Flournoy R, E., Altman, D. E., Blendon, R. J., Benson, J. M., \& Rosenbaum, M. D. (2000). Health information, the Internet, and the Digital Divide. Health Affairs, 19, 255-265.

Brown, A.E., \& Lee, M.D. (2011). Maternal child-feeding style during the weaning period: association with infant weight and maternal eating style. Eating Behaviors, 12, 108-111.

Brunstrom, J. M. (2005). Dietary learning in humans: Directions for future research. Physiology \& Behavior, 85(1), 57-65.

Brunstrom, J.M. (2007). Associative learning and the control of human dietary behavior. Appetite, 49, 268-271

Brunstrom, J. M., \& Mitchell, G.L. (2006). Effects of distraction on the development of satiety. British Journal of Nutrition, 96, 761-769.

Brunstrom, J. M., \& Mitchell, G.L. (2007). Flavor-nutrient learning in restrained and unrestrained eaters. Physiology \& Behavior, 90(1), 133-141.

Brunstrom, J.M., Mitchell, G.L., \& Baguley, T.S. (2005). Potential early-life predictors of dietary behaviour in adulthood: a retrospective study. International Journal of Obesity, 29, 463-474.

Bryant-Waugh, R., Markham, L., Kreipe, R.E., \& Walsh, B.T. (2010). Feeding and eating disorders in childhood. International Journal of Eating Disorders, $43,98-111$. 
Campbell, K., Andrianopoulos, N., Hesketh, K., Ball, K., Crawford, D., Brennan, L., Corsini, N., \& Timperio, A. (2010). Parental use of restrictive feeding practices and child BMI z-score. A 3-year prospective cohort study. Appetite, 55, 84-88.

Carper, J.L., Fisher, J.O., \& Birch, L.L. (2000). Young girls' emerging dietary restraint and disinhibition are related to parental control in child feeding. Appetite, 35(2), 121-129.

Carruth, B.R., \& Skinner, J.D. (2000). Revisiting the picky eater phenomenon: Neophobic behaviors of young children. Journal of the American College of Nutrition, 19(6), 771-780.

Carruth, B.R., \& Skinner, J.D. (2001). Mothers' sources of information about feeding their children ages 2 to 54 months. Journal of Nutrition Education, 33(3), 143-147.

Carruth, B.R., Ziegler P.J., Gordon A., \& Barr S.I. (2004). Prevalence of picky eaters among infants and toddlers and their caregivers" decisions about offering a new food. Journal of the American Dietetic Association, 104, 5764.

Cashdan, E. (1994). A sensitive period for learning about food. Human Nature, $5,279-291$

Cashdan, E. (1998). Adaptiveness of food learning and food aversions in children. Social Science Information, 37, 613-632.

Chatoor, I., Hirsch, R., Ganiban, J., Persinger, M., \& Hamburger, E. (1998). Diagnosing infantile anorexia: the observation of mother-infant interactions. Journal of the American Academy of Child Psychology, 37, 959-967. 
Clark, H.R., Goyder, E., Bissell, P., et al. (2007). How do parents' child-feeding behaviours influence child weight? Implications for childhood obesity policy. Journal of Public Health, 29, 132-141.

Cooke, L. (2007). The importance of exposure for healthy eating in childhood: a review. Journal of Human Nutrition \& Dietetics, 20, 294-301.

Coulthard, H., \& Harris, G. (2003). Early food refusal: the role of maternal mood. Journal of Reproductive \&Infant Psychology, 21(4), 335-345.

Craigie, A.M., Lake, A.A., Kelly, S.A., Adamson, A.J., \& Mathers, J.C. (2011). Tracking of obesity-related behaviours from childhood to adulthood: A systematic review. Maturitas, 70(3), 266-284.

Crist, W., McDonnell, P., Beck, M., Gillespie, C.T., Barrett, P., \& Matthews, J. (1994). Behavior at mealtimes and nutritional intake in the young child with cystic fibrosis. Developmental Behavioural Paediatrics, 15, 157-161.

Deering, S.H., Hodor, J.G., Wylen, M., Poggi, S., Nielsen, P.E., Satin, A.J. (2006).Additional Training with an Obstetric Simulator Improves Medical Student Comfort with Basic Procedures. Simulation in Healthcare: Journal of the Society for Medical Simulation, 1(1), 32-34.

De Houwer, J., Thomas, S., \& Baeyens, F. (2001). Associative learning of likes and dislikes: a review of 25 years of research on human evaluative conditioning. Psychology Bulletin, 127(6), 853-869.

Dennison, B.A. (1996). Fruit juice consumption by infants and children: a review. Journal of the American College of Nutrition, 15(5), 4S-11S.

Department of Health. (2009). Birth to Five (p.59). http://www.dh.gov.uk/prod consum dh/groups/dh digitalassets/@dh/@en/ 
@ps/@sta/@perf/documents/digitalasset/dh 117167.pdf - downloaded 24th April 2012.

Detecon Consulting (2011). Applications for Good. Mobile Health Applications for Low Socio-Economic Communities.

http://www.slideshare.net/applicationsforgood/mobile-health-apps-for-lowincome-communities - downloaded $13^{\text {th }}$ February 2012.

Dovey, T.M., Farrow, C.V., Martin, C.I., Isherwood, E., \& Halford, J.C.G. (2009). When does food refusal require professional intervention? Current Nutrition \& Food Science, 5, 160-171.

Dovey, T.M., Staples, P.A., Gibson, E.L., \& Halford, J.C.G. (2008). Food neophobia and 'picky/fussy' eating in children: A review. Appetite, 50, 181193.

Drucker, R.R, Hammer, L.D., Agras, W.S., \& Bryson, S. (1999). Can mothers influence their child's eating behavior? Journal of Developmental \& Behavioral Pediatrics, 20(2), 88-92.

Duniz, M., Scheer, P.J., Trojovsky, A., Kaschnitz, W., Kvas, E., \& Macari, S. (1996). Changes in psychopathology of parents of NOFT (non-organic failure to thrive) infants during treatment. European Child \& Adolescent Psychiatry, 5, 93-100.

Eliassen, E., Miller, K., \& Guskey, T. (2010). Parent Feeding Strategies: Behavior Change Following an Intervention Program. Journal of the American Dietetic Association, 110(9), p.A97.

Essery, E.V., DiMarco, N.M., Rich, S.S. \& Nichols, D.L. (2008). Mothers of Preschoolers Report Using Less Pressure in Child Feeding Situations 
Following a Newsletter Intervention. Journal of Nutrition Education \& Behavior, 40(2), 110-115.

Fägerskiöld, A.M., Wahlberg, V., \& Ek, A-C. (2001). Maternal expectations of the child health nurse. Nursing \& Health Sciences, 3(3), 139-147.

Faith, M.S., Berkowitz, R.I., Stallings, V.A., Kerns, J., Storey, M., \& Stunkard, A.J. (2004). Parental Feeding Attitudes and Styles and Child Body Mass Index: Prospective Analysis of a Gene-Environment Interaction. Pediatrics, 114(4), $429-436$.

Farrow, C. (2011). The impact of responsive parental feeding practices upon subsequent child eating and growth: findings from the UK. Royal Society funded Indo-UK symposia. Hyderabad, India.

Farrow, C.V., \& Blissett, J. (2006a). Does maternal control during feeding moderate early infant weight gain? Pediatrics, 118(2), 293-298.

Farrow, C.V., \& Blissett, J. (2006b). Maternal cognitions, psychopathologic symptoms, and infant temperament as predictors of early infant feeding problems: a longitudinal study. International Journal of Eating Disorders, 39, 128-134.

Farrow, C.V., \& Blissett, J. (2008). 'Controlling Feeding Practices: Cause or Consequence of Early Child Weight. Pediatrics, 121, 164-169.

Festinger, L. (1950). Informal social communication. Psychological Review, 57, 271-82.

Fraser, K., Wallis, M., \& St John, W. (2004). Improving children's problem eating and mealtime behaviours: An evaluative study of a single session parent education programme. Health Education Journal, 63(3), 229-241. 
Fisher, J.O., \& Birch, L.L. (2002). Eating in the absence of hunger and overweight in girls from 5 to 7 years of age. American Journal of Clinical Nutrition, 76(1), 226-231.

Fisher, J.O., \& Kral, T.V.E. (2008). Super-size me: Portion size effects on young children's eating. Physiology \& Behavior, 94, 39-47.

Fisher, J.O., Mitchell, D.C., Smiciklas-Wright, H., \& Birch, L.L. (2002). Parental influences on young girls' fruit and vegetable, micronutrient, and fat intakes. Journal of the American Dietetic Association, 102, 58-64.

Flurry (2011a). Mobile Apps Put the Web in Their Rear-view Mirror. http://blog.flurry.com/bid/63907/Mobile-Apps-Put-the-Web-in-Their-Rearview-Mirror - downloaded 22nd June 2011.

Flurry (2011b). Smartphone Apps in Europe: The 8th Mass Market Media Channel. http://blog.flurry.com/bid/63381/Smartphone-Apps-in-Europe-The8th-Mass-Market-Media-Channel - downloaded 22nd June 2011.

Galloway, A.T., Fiorito, L.M., Francis, L.A., \& Birch, L.L. (2006). 'Finish your soup'. Counterproductive effects of pressuring children to eat on intake and affect. Appetite, 46, 318-323

Galloway, A. T., Fiorito, L. M., Lee, Y., \& Birch, L. L. (2005). Parental pressure, dietary patterns, and weight status in girls who are 'picky eaters'. Journal of the American Dietetic Association, 105, 541-548.

Gibbons, M.C., Wilson, R.F., Samal, L., Lehmann, C.U., Dickersin, K., Lehmann, H.P., et al. (2009). Impact of Consumer Health Informatics Applications. Evidence Report/Technology Assessment No. 188. (Prepared by Johns Hopkins University Evidence-based Practice Center under contract No. 
HHSA 290-2007-10061-I). AHRQ Publication No. 09(10)-E019. Rockville, MD. Agency for Healthcare Research and Quality. October 2009. http://www.ahrq.gov/downloads/pub/evidence/pdf/chiapp/impactchia.pdf downloaded 13th February 2012.

Gibson, E.L., Wainwright, C.J., \& Booth, D.A. (1995). Disguised protein in lunch after low-protein breakfast conditions food -flavor preferences dependent on recent lack of protein-intake. Physiology \& Behavior, 58, 363-371.

Gildea, A., Sloan, S., \& Stewart, M. (2009). Sources of feeding advice in the first year of life: who do parents value? The Journal of the Community Practitioners' \& Health Visitors' Association, 82(3), 27-31.

Gregory, J.E., Paxton, S.J., \& Brozovic, A.M. (2010a). Pressure to eat and restriction are associated with child eating behaviours and maternal concern about child weight, but not child body mass index, in 2- to 4-year-old children. Appetite, 54(3), 550-556.

Gregory, J.E., Paxton, S.J., \& Brozovic, A.M. (2010b). Maternal feeding practices, child eating behaviour and body mass index in preschool-aged children: a prospective analysis. The International Journal of Behavioral Nutrition \& Physical Activity, 7, 55-65.

Greenhalgh, J., Dowey, A., Horne, P., Lowe, C.F., Griffiths, J.H., \& Whitaker, C.J. (2009). Positive- and negative peer modelling effects on young children's consumption of novel blue foods. Appetite, 52, 646-653.

Hamilton, B.E., Martin, J.A., \& Ventura, S.J. (2011). Births: Preliminary Data for 2010. National Vital Statistics Report, 60(2), 1-25. 
Havermans, R.C., \& Jansen, A. (2007). Increasing children's liking of vegetables through flavour-flavour learning. Appetite, 48(2), 259-262.

Haycraft, E. L., \& Blissett, J.M. (2008). Maternal and paternal controlling feeding practices: Reliability and relationships with BMI. Obesity, 16(7), 1552-1558.

Haywood, P., \& McCann, J. (2009). A brief group intervention for young children with feeding problems. Clinical Child Psychology \& Psychiatry, 14(3), 361372.

Hendy, H.M., \& Raudenbusch, B. (2000). Effectiveness of teacher modelling to encourage acceptance in preschool children. Appetite, 34, 61-76.

Heim, S., Stang, J., \& Ireland, M. (2009) A garden pilot project enhances fruit and vegetable consumption among children. Journal of the American Dietetic Association, 109, 1220-1226.

Heinig, M.J., Ishii, K.D., Banuelos, J.L., Campbell, E., O’Loughlin, C., \& Becerra, L.E.V. (2009). Sources and acceptance of infant-feeding advice among lowincome women. Journal of Human Lactation, 25(2), 163-172.

Horodynski, M., Olson, B., Arndt, M.J., Brophy-Herb, H., Shirer, K., \& Shemanski, R. (2007). Low-income mothers' decisions regarding when and why to introduce solid foods to their infants: Influencing factors. Journal of Community Health Nursing, 24(2), 101-118.

Horton, R. (2010) School dinners: a healthy choice? The Lancet (Editorial), 376, 69.

Hughes, S.O., Power, T.G., Fisher, J.O., Mueller, S., \& Nicklas, T.A. (2005). Revisiting a neglected construct: parenting styles in a child-feeding context. Appetite, 44, 83-92. 
Hunter, J.L. (2005). Cervical cancer educational pamphlets: Do they miss the mark for Mexican immigrant women's needs? Cancer Control, 12(2), 42-50. Inglis, N.J., Docherty, A., \& Pryke, R. (2010). Evaluation of the 'Mealtime Magic' brief leaflet-based intervention in general practice. Primary Health Care Research \& Development, 11, 166-179.

Jansen, A., \& Tenney, N. (2001). Seeing mum drinking a 'light' product. Is social learning a stronger determinant of taste preference acquisition than caloric conditioning? European Journal of Clinical Nutrition, 55, 418-422.

Johnson, S.L., McPhee, L., \& Birch, L.L. (1991). Conditioned preferencesyoung children prefer flavors associated with high dietary-fat. Physiology \& Behavior, 50, 1245-1251.

Jones, C.J., \& Bryant-Waugh, R. (2012). Development and pilot of a group skills-and-support intervention for mothers of children with feeding problems. Appetite, 58(2), 450-456.

Kern, D.L., McPhee, L., Fisher, J., Johnson, S., \& Birch, L.L. (1993). The postingestive consequences of fat condition preferences for flavors associated with high dietary-fat. Physiology \& Behavior, 54, 71-76.

Klesges, R.C., Coates, T.J., Brown, G., Sturgeon-Tillisch, J., MoldenhauerKlesges, L.M., Holzer, B., Woolfrey, J., \& Vollmer, J. (1983). Parental influences on children's eating behavior and relative weight. Journal of Applied Behavior Analysis, 16(4), 371-378.

Klesges, R.C., Malott, J.M., Boschee, P.F., \& Weber, J.M. (1986). The effects of parental influences on children's food intake, physical activity, and relative weight. International Journal of Eating Disorders, 5(2), 335-345. 
Larkin, H. (2011). Mhealth. Hospitals and Healthcare Network Magazine, April 2011, pp. $22-26$.

http://www.hhnmag.com/hhnmag app/jsp/articledisplay.jsp?dcrpath=HHNM AG/Article/data/04APR2011/0411HHN Coverstory\&domain=HHNMAG downloaded $13^{\text {th }}$ February 2012

Lee. H., \& Keller, K, L. (2012). Children who are pressured to eat at home consume fewer high-fat foods in laboratory test meals. Journal of the Academy of Nutrition \& Dietetics, 112(2), 271-275.

Lindberg, L., Bohlin, G., Hagekull, B., \& Palmerus, K. (1996). Interactions between mothers and infants showing food refusal. Infant Mental Health Journal, 17, 334-337.

Lumeng, J.C., Ozbeki, T.N., Appugliese, D.O., Kaciroti, N., Corwyn, R.F., \& Bradley, R.H. (2012).Observed assertive and intrusive maternal feeding behaviors increase child adiposity. American Journal of Clinical Nutrition, 95(3), 640-647.

Mahoney, G., Kaiser, A., Girolametto, L., \& MacDonald, J. (1999). Parent education in early intervention: A call for renewed focus. Topics in Early Childhood Special Education, 19, 131-146.

Maier, A., Chabanet, C., Schaal, B., Leathwood, P., \& Issanchou, S. (2007). Food-related sensory experience from birth through weaning: Contrasted patterns in two nearby European regions. Appetite, 49, 429-40.

March, M., \& Cohen, P. (1990). Early childhood eating behaviors and adolescent eating disorders. Journal of the American Academy of Child \& Adolescent Psychiatry, 29, 112-117. 
Mertz, L. (2012). Ultrasound? Fetal Monitoring? Spectrometer? There's an App for That!: Biomedical Smart Phone Apps Are Taking Healthcare by Storm. IEEE Pulse, 3(2), 16-21.

McConahy, K.L., Smiciklas-Wright, H., Mitchell, D.C., \& Picciano, M.F. (2004). Portion Size of Common Foods Predicts Energy Intake among PreschoolAged Children. Journal of the American Dietetic Association, 104(6), 975979.

Mitchell, G.L., Farrow, C., \& Haycraft, E. (2012). 'App'lying research: Utilising apps to provide feeding advice and resources to parents. Poster presented at the Research That Matters Conference, March 2012, Loughborough University, UK.

Mueller, M. M., Piazza, C. C., Moore, J. W., Kelley, M. E., Bethke, S. A., \& Pruett, A. E., et al. (2003).Training parents to implement pediatric feeding protocols. Journal of Applied Behavior Analysis, 36, 545-562.

Murphy, S., \& Smith, C. (1993). Crutches, confetti or useful tools? Professionals, views on and use of health education leaflets. Health Education Research. Theory \& Practice, 8(2), 2050215.

Mustonen, S., \& Tuorila, H. (2010). Sensory education decreases food neophobia score and encourages trying unfamiliar foods in 8-12-year-old children. Food Quality \& Preference, 21, 353-360.

Nicklas, T.A., \& Hayes, D. (2008). Position of the American Dietetic Association: nutrition guidance for healthy children ages 2 to 11 years. Journal of the American Dietetic Association, 108(6), 1038-1044. 
Office for National Statistics (2011). Statistical Bulletin: Births and Deaths in England and Wales, 2010.

http://www.ons.gov.uk/ons/search/index.html?newquery=2010+BIRTHS downloaded $24^{\text {th }}$ November 2011

Ogden, J., Reynolds, R., \& Smith, A. (2006) Expanding the concept of parental control. A role for overt and covert control in children's snacking behaviour? Appetite, 47, 100-106.

Olson, B.H., Horodynski, M.A., Brophy-Herb, H., \& Iwanski, K.C. (2010). Health professionals' perspectives in the infant feeding practices of low income mothers. Maternal \& Child Health Journal, 14, 75-85.

Orrell-Valente, J.K., Hill, L.G., Brechwald, W.A., Dodge, K.A., Pettit, G.S., \& Bates, J.E. (2007). "Just three more bites": An observational analysis of parents' socialization of children's eating at mealtime. Appetite, 48, 37-45.

Olvera, N., \& Power, T.G. (2010). Parenting styles and obesity in Mexican American children: A longitudinal study. Journal of Pediatric Psychology, 35(3), 243-249.

Palfreyman, Z., Haycraft, E., \& Meyer, C. (in press). Development of the Parental Modelling of Eating Behaviours Scale (PARM): Links with food intake among children and their mothers. Maternal and Child Nutrition. DOI: 10.1111/j.1740-8709.2012.00438.x

Patrick, H., Nicklas, T.A., Hughes, S.O., \& Morales, M. (2005). The benefits of authoritative feeding style: caregiver feeding styles and children's food consumption patterns. Appetite, 44, 243-249. 
Petrasova, A., Czanner, S., Chalmers, A., Farrer, J.V., \& Wolke, D. (2010a). The playability evaluation of virtual baby feeding application. 2010 Second International Conference on Games and Virtual Worlds for Serious Application, p.95-100.

Petrasova, A., Czanner, G., Happa, J., Czanner, S., Wolke, D., \& Chalmers, A. (2010b). Assessing a virtual baby feeding training system. Proceedings of the 7th International Conference on Computer Graphics, Virtual Reality, Visualisation and Interaction in Africa, p.37-44.

Petrasova, A., Farrer, J.V., Czanner, S., Chalmers, A., \& Wolke, D. (2009a). Building virtual environment for feeding scenario simulation. Central European Seminar on Computer Graphics for students, p.20-21. http://www.cescg.org/CESCG-2009/index.html - downloaded on 22nd June 2011.

Petrasova, A., Farrer, J.V., Czanner, S., Chalmers, A., \& Wolke, D. (2009b). User Interface for Assisting Babies with Feeding Disorders. 2009 International Conference in Cyber Worlds, p.287-291.

Pliner, P., \& Hobden, K. (1992). Development of a scale to measure the trait of food neophobia in humans. Appetite, 19(2), 105-120.

Powell, F.C., Farrow, C.V. \& Meyer, C. (2011). Food avoidance in children. The influence of maternal feeding practices and behaviours. Appetite, 58(2), 450-456.

Pugliese, M.T., Weyman-Daum, M., Moses, N., \& Lifshitz, F. (1987). Parental Health Beliefs as a Cause of Nonorganic Failure to Thrive. Pediatrics, 80(2), $175-182$ 
Puhl, R.W., \& Schwartz, M.B. (2003). If you are good you can have a cookie: How memories of childhood food rules link to adult eating behaviors. Eating Behaviors, 4(3), 283-293.

Reau, N.R., Senturia, Y.D., Lebailly, S.A., \& Christoffel, K.K. (1996). Infant and toddler feeding patterns and problems: normative data and a new direction. The Pediatric Research Group. Journal of Developmental and Behavioural Pediatrics, 17, 149-153.

Reverdy, C., Chesnel, F., Schlich, P., Köster, E.P., \& Lange, C. (2009). Effect of sensory education on willingness to taste novel food in children. Appetite, $51,156-165$

Rhee, K.E., Lumeng, J.C., Appugliese, D.P., Kaciroti, N., \& Bradley, R.H. (2006). Parenting Styles and Overweight Status in First Grade. Pediatrics, 117(6), 2047-2054

Rigal, N., Chabanet, C., Issanchou, S., \& Monnery-Patris, S. (2012). Links between maternal feeding practices and children's eating difficulties. Validation of French tools. Appetite, 58, 629-637.

Robinson, S. (2000). Children's perceptions of who controls their food. Journal of Human Nutrition \& Dietetics, 13, 163-171.

Rosenstein, D., \& Oster, H. (1990). Differential facia responses to four basic tastes in newborns. Child Development, 59, 1555-1568.

Rozin, P., \& Vollmecke, T. (1998). Food likes and dislikes. Annual Review of Nutrition, 6, 433-456. 
Sanders, M.R., Patel, R.K., le Grice, B., \& Shephard, R.W. (1993). Children with persistent feeding difficulties: An observational analysis of the feeding interactions of problem and non-problem eaters. Health Psychology, 12, 6473.

Savage, J.S., Fisher, J.O., \& Birch, L.L. (2007) Parental influence on eating behavior: conception to adolescence. Journal of Law, Medicine \& Ethics, 35(1), 22-34.

Scarborough, P., Bhatnagar, P., Wickramasinghe, K.K., Allender, S., Foster, C., \& Rayner, M. (2011). The economic burden of ill health due to diet, physical inactivity, smoking, alcohol and obesity in the UK: an update to 2006-07 NHS costs. Journal of Public Health, 33(4): 527-535.

Schank, R.C., Berman, T.R., \& Macpherson, K.A. (1999). Learning by doing. In Instructional Design Theories and Models: A New Paradigm of Instructional Theory, Volume II. Reigeluth, C.M. (Ed.) Routledge (2 ${ }^{\text {nd }}$ Ednt).

Schwartz, C., Issanchou, S., \& Nicklaus, S. (2009). Developmental changes in the acceptance of the five basic tastes in the first year of life. British Journal of Nutrition, 102, 1375-1385.

Schwartz, C., Scholtens, P.A.M.J., Lalanne, A., Weenen, H., \& Nicklaus, S. (2011). Development of healthy eating habits early in life. Review of recent evidence and selected guidelines. Appetite, 57, 796-807.

Shepard, R., \& Dennison, C.M. (1996). Influences on adolescent food choice. Proceedings of the Nutritional Society, 55, 345-357. 
Singer, L.T., Song, L.Y., Hill, B.P., \& Jaffe, A.C. (1990). Stress and depression in mothers of failure to thrive children. Journal of Pediatric Psychology, 15, 711-720.

Spender, Q., Stein, A., Dennis, J., Reilly, S., Percy, E., \& Cave, D. (1996). An exploration of feeding difficulties in children with Down's syndrome. Developmental Medicine \& Child Neurology, 38, 681-694.

Steiner, J.E. (1979). Human facial expressions in response to taste and smell stimulation. Advances in Child Development Behavior, 13, 257-295.

Stifter, C.A., Anzman-Frasca, S., Birch, L.L., \& Voegtline, K. (2011). Parent use of food to soothe infant/toddler distress and child weight status. An exploratory study. Appetite, 57(3), 693-699.

Tan, C.C., \& Holub, S.C. (2011). Children's Self-Regulation in Eating: Associations with Inhibitory Control and Parents' Feeding Behavior. Journal of Pediatric Psychology, 36(3), 340-345.

Ünlü, G., Aras, S., Guvenir, T., Buyukgebiz, B., \& Bekem, O. (2006). Family functioning, personality disorders and depressive and anxiety symptoms among mothers of children with food refusal. Turkish Journal of Psychiatry, $17,1-8$.

United Nations (2011). World Population Prospects; the 2010 Revision. http://esa.un.org/unpd/wpp/Excel-Data/fertility.htm - downloaded on $7^{\text {th }}$ August 2012.

Ventura, A., \& Birch, L. (2008). Does parenting affect children's eating and weight status? International Journal of Behavioral Nutrition \&Physical Activity, 5, 15. 
Wake, M., Nicholson, J.M., Hardy, P., \& Smith, K. (2007). Preschooler Obesity and Parenting Styles of Mothers and Fathers: Australian National Population Study. Pediatrics, 120(6), 1520-1527.

Walker, S.K. (2005). Use of a Parenting Newsletter Series and Other ChildRearing Information Sources by Mothers of Infants. Family \& Consumer Sciences Research Journal, 34(2), 153-172.

Wardle, J., Carnell, S., \& Cooke, L. (2005). Parental control over feeding and children's fruit and vegetable intake: How are they related? Journal of the American Dietetic Association, 105, 227-232.

Wardle, J., Cooke, L.J., Gibson, E.L., Sapochnik, M., Sheiham, A., \& Lawson, M. (2003). Increasing children's acceptance of vegetables: A randomised trial of parent-led exposure. Appetite, 40, 155-162.

Wardle, J., \& Huon, G. (2000). An experimental investigation of the influence of health information on children's taste preferences. Health Education Research, 15, 39-44.

Webber, L., Cooke, L., Hill, C., \& Wardle, J. (2010). Associations between Children's Appetitive Traits and Maternal Feeding Practices. Journal of the American Dietetic Association, 110, 1718-1722.

Whelan, E., \& Cooper, P.J. (2000). The association between childhood feeding problems and maternal eating disorder. A community study. Psychological Medicine, 30, 69-77.

Zajonc, R. (1968). Attitudinal effects of mere exposure. Journal of Personality \& Social Psychology, 9(2), 1-27. 
Zandstra, E.H., Stubenitsky, K., De Graaf, C., \& Mela, D.J. (2002). Effects of learned flavour cues on short-term regulation of food intake in a realistic setting. Physiology \& Behavior, 75, 83-90. 